\title{
CLINICAL PROTEOMICS IN KIDNEY DISEASE: FROM DISCOVERY TO CLINICAL APPLICATION
}

Martin Pejchinovski, Harald Mischak

Mosaiques Diagnostics GmbH, Hannover, Germany

Corresponding author: Martin Pejchinovski, Clinical Proteomics, Mosaiques diagnostics GmbH, Rotenburger Str. 20, D-30659 Hannover, Germany, E-mail: pejchinovski@mosaiques-diagnostics.com, Phone: +49 (0)511 554744 38, Fax: +49(0)51155474431

\begin{abstract}
Proteome analysis has been applied in multiple studies in the context of chronic kidney disease, aiming at improving our knowledge on the molecular pathophysiology of the disease. The approach is generally based on the hypothesis that proteins are key in maintaining kidney function, and disease is a clinical consequence of a significant change of the protein level. Knowledge on critical proteins and their alteration in disease should in turn enable identification of ideal biomarkers that could guide patient management. In addition, all drugs currently employed target proteins. Hence, proteome analysis also promises to enable identifying the best suited therapeutic target, and, in combination with biomarkers, could be used as the rationale basis for personalized intervention. To assess the current status of proteome analysis in the context of CKD, we present the results of a systematic review, of up-to-date scientific research, and give an outlook on the developments that can be expected in near future. Based on the current literature, proteome analysis has already seen implementation in the management of CKD patients, and it is expected that this approach, also supported by the positive results generated to date, will see advanced high-throughput application.
\end{abstract}

Keywords: proteome analysis, biomarkers, chronic kidney disease

\section{INTRODUCTION}

Chronic diseases are among the biggest burdens of the modern society, and associated with ever-increasing challenges, as a result of the increase in life expectancy. Among these chronic diseases, chronic kidney disease (CKD) is affecting about $10 \%$ of the population [1]. It is known as a heterogeneous disease generally characterized by abnormalities in kidney structure and function lasting for more than three months. CKD and its final stage, end stage renal disease (ESRD), has a major impact on the patient's life quality (dialysis, side effects of immunosuppressive drugs after kidney transplantation). Importantly, the total annual costs of CKD in Europe are estimated to exceed 100 billion $€[2]$. Taking into account the increase in life expectancy, the overall health costs are estimated to further increase by $5-10 \%$ per year (Pontillo and mischak 2017). As such, from a political and societal point of view, a plan on how to counteract this development is urgently required.

Kidneys are one of the most important filters of the human body. They are a delicate and highly organized structure, containing over 1 million 
nephrons consisting of a multicellular filtration unit, the glomerulus, and associated complex structures for processing and concentrating the primary urine, the renal tubules (Figure 1). The network of capillaries, glomeruli filter the blood, and produce the primary urine. The primary urine is further concentrated in the proximal tubule, where minerals, proteins, etc, are also reabsorbed. Both functions, filtration and reabsorption, are essential to sustain proper blood composition, and at the same time ensure elimination of "waste", compounds that may be harmful to the human body.

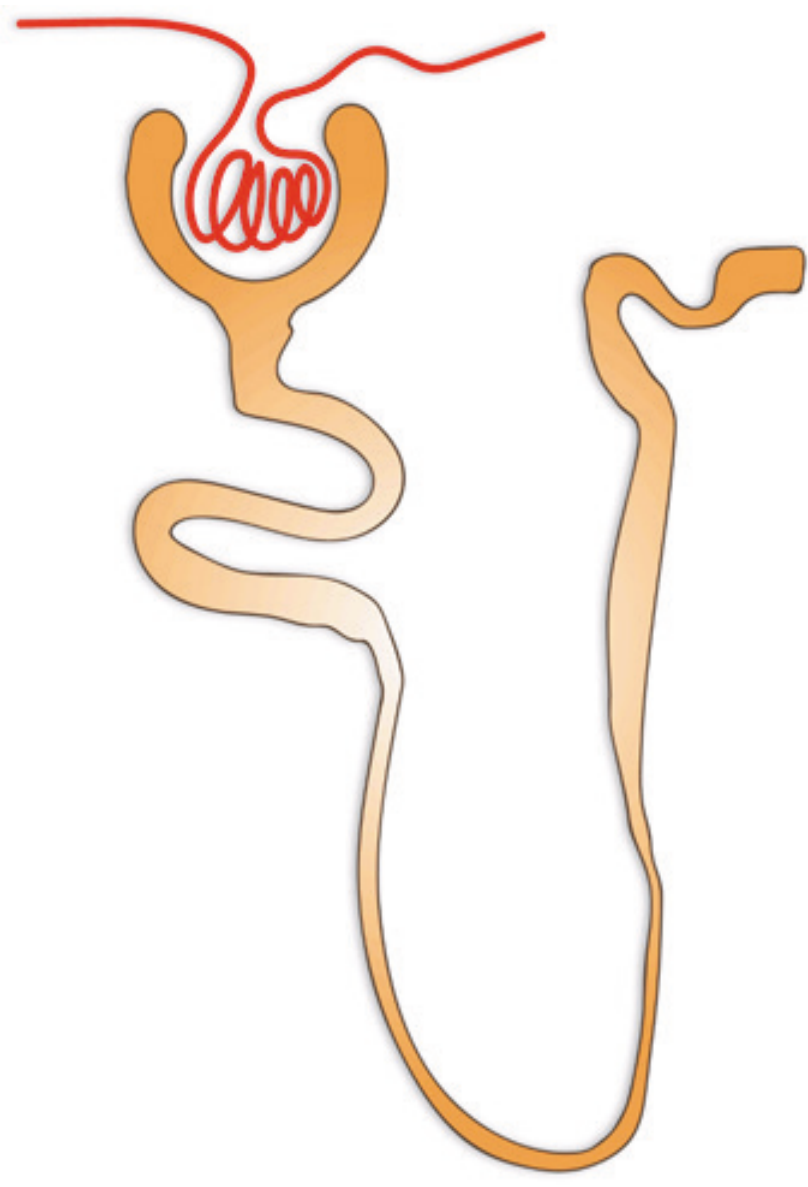

Figure 1. Schematic representation of a nephron: Blood is filtered in the glomerulum, and the resulting primary urine is concentrated in the tubulus, where valuable compounds (including minerals and water) are reabsorbed.

CKD persists, and typically progresses over a long period of time, until an endpoint, complete loss of kidney function (ESRD), is reached. During this time, a progressive loss of glomeruli function occurs, which, once lost, cannot be replaced. Simply stated: a destroyed nephron cannot be revived. Hence, once developed, CKD persists throughout the rest of life. In this scenario the only viable option is early intervention, before irreversible organ damage occurs. A simplified depiction of the development of CKD is given in Figure 2.

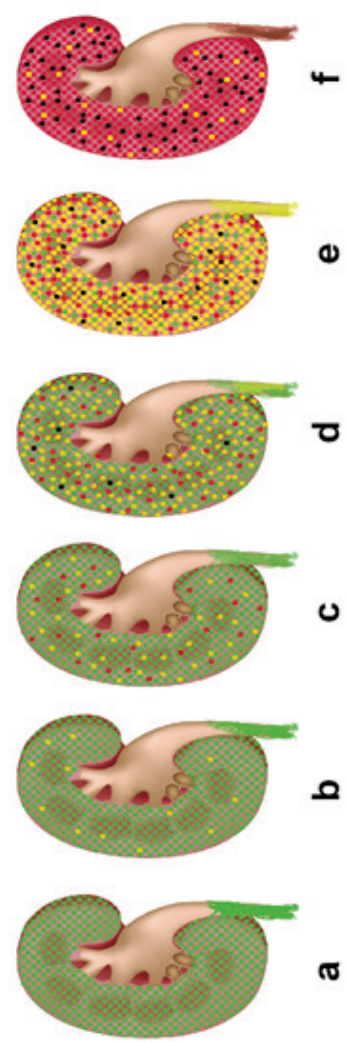

Figure 2. Schematic concept of CKD onset and progression. The kidney contains $\sim 1$ Mio filtration units, glomeruli. From the initially healthy status (green), some glomeruli experience pathological molecular changes (yellow) reversibly compromising their function. Without treatment, additional glomeruli will be damaged (c), a few also beyond the point where effective treatment may be possible (red). As pressure on the remaining intact glomeruli increases, damage of individual glomeruli is further accelerated (d), with now detectable impact on kidney functional parameters (albuminuria and/or eGFR), and first glomeruli lost (black). The molecular mechanisms are identical at this later stage to the beginning, but irreversible damage has occurred to multiple glomeruli, which cannot be repaired. Progression from d to e (established CKD, most glomeruli damaged, many beyond repair or completely lost) and $f(E S R D$, very few glomeruli still functional) cannot be prevented as a result of too high burden on the few remaining glomeruli. Prevention would have more likely been possible with intervention at (b) or (c), stages where molecular changes displayed by CKD273 are evident, but functional parameters are not yet affected. Reprinted from [2] with permission

Any development in the direction of preventing onset and progression of CKD requires: a) diagnosis of the early stage disease and prognosis with sufficient accuracy, and b) specific therapeutic drugs, or other means of specific intervention. 
Based on these requirements, multiple efforts are made towards early detection of CKD, at a point in time when the kidney is not yet irreversibly damaged. A main scope of research in this area was and is the identification of urinary peptides/ proteins that are indicative of early disease stage. The rationale prompting such research is briefly provided below:

Since the kidney, as any other organ, is built from proteins, its (chronic) damage is preceded and determined by protein changes. Proteomic changes appear even more relevant since proteins are the target of any pharmacological intervention. These facts have resulted in the hypothesis that knowledge on disease-specific proteomic changes enables early detection of disease (ideally when no irreversible structural damage has occurred) and guidance of intervention in a personalized way.

In fact, this approach is not limited to the kidney, numerous proteomic-based efforts are being undertaken in a multiple clinically relevant fields, but for this article we focus on proteomics in the context of CKD.

\section{Proteomic biomarkers in CKD}

A systematic review for original manuscripts dealing with "chronic kidney disease" and "proteome" as research topics, published since 2010 , resulted in a total of 283 retrieved manuscripts. When limiting to original manuscripts, that report on proteome analysis in the context of human CKD with a clearly defined clinical aim, this list is reduced to a total of 36 manuscripts (all listed in supplement 1). Of these, 23 were on urine, and 13 on plasma as investigated specimen. It was surprising to see that no manuscript investigating human kidney tissue could be retrieved. This may reflect the consequence of the difficulties when obtaining the kidney tissue, and the challenge due to the heterogeneity in the kidney tissue, as a result of the different structural components and cell types.

Urine is an excellent source of biomarkers in clinical proteomics [3] and evidently the preferred specimen for proteome analysis in the context of CKD. This is due to multiple issues, among others urine is thought to reflect kidney physiology very well, and that disease-indicative proteome changes should be detectable in urine in

\section{Diseases represented in the human urinary proteome database}

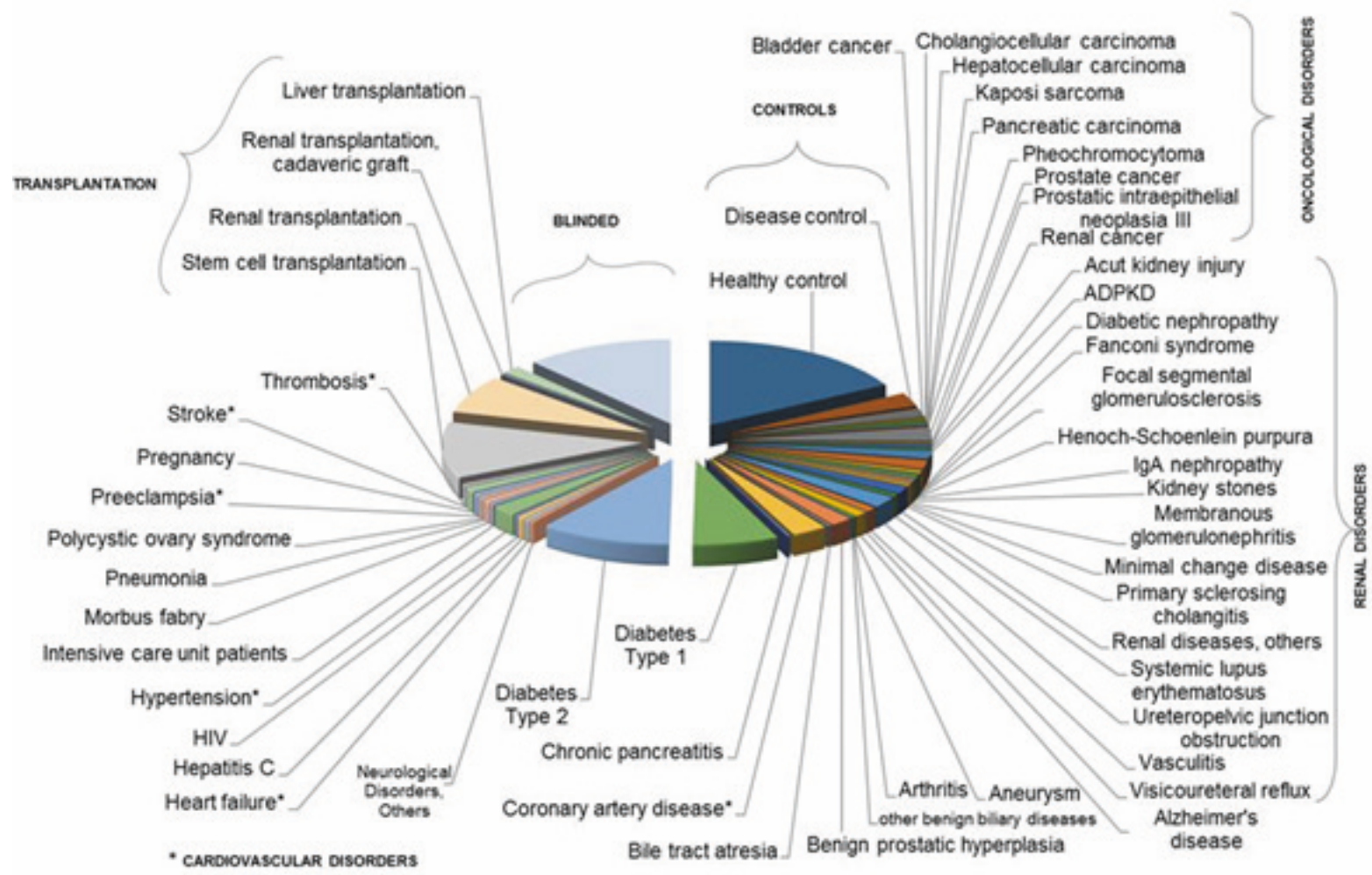

Figure 3. Content of the human urinary peptide database. To date, the human urinary proteome data base encompasses over 40000 independent CE-MS human urine data sets. It covers a wide range of diseases including cardiovascular, renal and hematological disease and a large variety of cancers. Reprinted from [6] with permission. 
a non-invasive way [4]. In addition, urine allows for multiple sampling, hence enabling non-invasive assessment of disease progression, but also of response to treatment [5].

Of the reports on urinary proteomics, more than half (14) were based on capillary electrophoresis coupled mass spectrometry (CE-MS). CE-MS was developed to enable reproducible proteome analysis of urine.

\section{CE-MS based urinary proteomics.}

Capillary electrophoresis coupled mass spectrometry appears particularly well suited to assess the low molecular weight proteins and peptides, typically present in urine. Its advantages have been outlined in several recent reviews, e.g. $[6,7]$. The technology was initially applied more than 10 years ago in the context of nephrological applications [8,9]. Further technical development resulted in the establishment of a robust platform technology [10] that has enabled the highly comparable analysis of over 40000 human urine samples of different etiologies [6], depicted in Figure 3. CE-MS has been applied in multiple other areas of clinical relevance (e.g. $[11,12,13])$.

Alkhalaf and colleagues investigated the validity of a urinary proteomics classifier for CKD in a first approach in a cross-sectional cohort [14]. This classifier, that was developed previously in a small study [15] and displayed the association of reduced urinary collagen fragments with $\mathrm{CKD}$, allowed separation of the cohort in a cross sectional blinded study $(\mathrm{n}=148)$ in cases and controls with an accuracy of $95 \%$, clearly demonstrating the validity of the approach, and generating the basis for further investigations.

In a more in-depth, multi-site study investigating proteomic differences between a cohort of 230 patients with CKD of different etiology, and 379 controls, Good and his colleagues identified 273 urinary peptides that differed significantly among patients with different types of CKD [16]. These peptides were combined using special algorithm-based software into one classifier, termed CKD273. The classifier is based on the rationale that the combination of multiple biomarkers effectively render a heterogeneous disease such as CKD, while single biomarkers typically show high variability and do not reflect disease complexity [17]. This can be compared to single versus multiple measurements: multiple analyses will always give much higher accuracy of the distribution of a specific compound. The majority of the biomarkers present in the CKD273 are fragments of extracellular matrix proteins and proteins involved in inflammation and linked to disease pathophysiology [18].

This CKD273 classifier that can be assessed within $1 \mathrm{~h}$ by CE-MS was then investigated for its value to improve detection of disease at an early stage in several, yet relatively small, studies. In a study including $>300$ samples from 35 patients, collected over 10 years, CKD273 significantly outperformed albuminuria in predicting onset of diabetic nephropathy [19]. Similar positive results were obtained in other clinical studies. In addition, Roscioni et al. demonstrated a significant value of CKD273 in predicting a transition from normo- to micro-, or from micro- to macroalbuminuria in a cohort of 88 patients with 3 year follow-up [20]. CKD273 also demonstrated value in predicting progression at later stages of CKD. In a prospective study including 53 patients at different stages of CKD that were followed for an average of 3.6 years, Argiles et al. found that a low scoring in CKD273 was associated with good prognosis, none of the patients with CKD273<0.55 progressed to ESRD or death [21]. Furthermore, in a cohort encompassing 18 patients with CKD and 17 controls, Ovrehus et al., [22] demonstrated a significant improvement of the classification of patients by CKD273, in comparison to albuminuria.

In spite of CE-MS great potential for clinical proteomics, MALDI-MS was investigated for its ability to generate similar information (allow assessing CKD), but at lower laboratory cost [23]. The study including 137 subjects clearly showed superior performance of CE-MS over MALDI-MS, hence, replacement of CE-MS with MALDI-MS as an alternative technology while keeping the performance does not appear possible. To investigate if the performance of CE-MS-based urinary proteomics could be further improved by other biomarkers, Nkuipou-Kenfack et al. [24] investigated whether the addition of metabolomics data could improve performance of CKD273, in a cohort of 49 patients representing different stages of CKD. While the authors found significant association of several urine and plasma metabolites with CKD and also with CKD progression, no significant added benefit of metabolomics on top of CKD273 could be detected.

These promising results led to the initiation of the first urine proteomics guided intervention trial, PRIORITY $[25,26]$. In this randomized con- 
trolled clinical trial funded by the European Commission (www.eu-priority.org), more than 2000 diabetic patients that do not (yet) show any sign of CKD have been enrolled and examined using CKD273. An outline of the trial design is shown tional multi-center cohort of 1990 individuals, including 522 with follow-up data. CKD273 performed significantly better in detecting and predicting progression of CKD than urinary albumin. In addition, CKD273 was also more sensitive

\section{PRIORITY: RCT employing CKD273 for stratification Targeted therapy/personalized medicine in Nephrology}

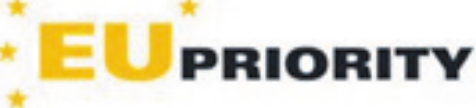

\author{
Early prediction of diabetic nephropathy \\ via urinary proteome analysis
}

- Multicenter study

- 15 partners in Europe

- 6 years

\section{- 3280 normoalbuminuric type 2 diabetic patients}

- Stratification into low and high risk patients

- High risk patients will be randomly assigned to aldosterone blocker spironolactone $25 \mathrm{mg}$ or placebo therapy on top of optimal standard therapy

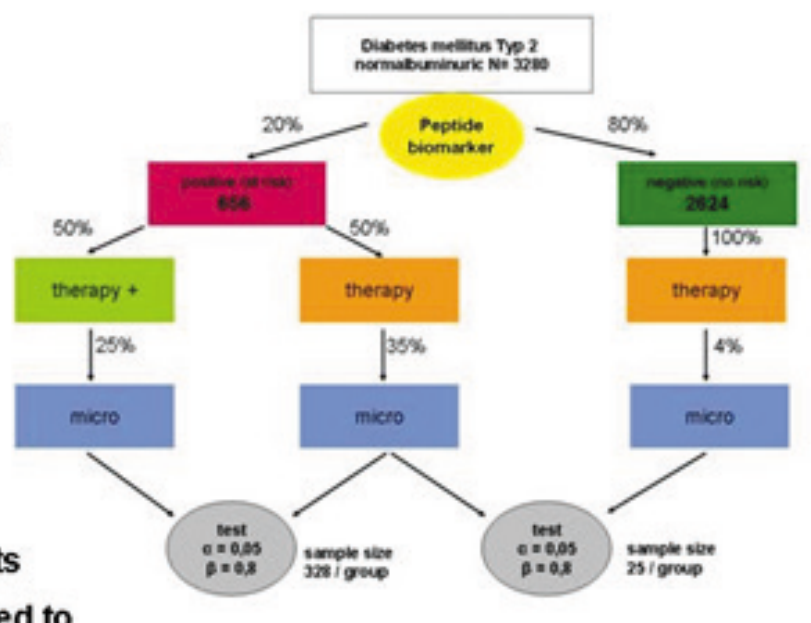

Siny et al. (2014) Nephrol Dial Transplant Schanstra and Mischak (2015) Pediatr Nephrol

Figure 4. CE-MS biomarker guided patient stratification. In the PRIORITY clinical trial (NCT 02040441), CKD273 is implemented for patient stratification into the high (red box) and low (green box) risk groups for the development of CKD. The low risk group, which likely will not develop CKD, will not receive any additional treatment (as this may bring harm, but likely no benefit). The high-risk patients will be randomized to the therapy with the investigational drug (low dose spironolactone) or placebo. A total of 2000 patients are included in the study. Reprinted from [72] with permission

in Figure 4. Patients positive for CKD273 (indicating early stages of CKD) are randomized for a low dose treatment with an aldosterone antagonist (spironolactone) with renoprotective properties or placebo. If successful, the trial will not only further verify the value of CKD273 in early detection of CKD, but will especially demonstrate the positive effect of intervention by spironolactone. Given the reports on benefit of spironolactone in the context of diabetic nephropathy [27], and the very recent demonstration of the predictive value of CKD273 for response to spironolactone [28], a positive outcome of the study appears certain.

In parallel, the results from the smaller studies mentioned above paved the way towards further evaluation of this novel approach in large cohorts of patients, including diabetic patients, but also the general population. Schanstra et al. [29] investigated urinary peptides in a large cross-sec- for identifying patients with rapidly progressing CKD. Most of the individual peptides associated with progression of CKD originated from proteins related to inflammation and tissue repair. These results indicate that the knowledge on the urinary peptides allows insight into ongoing pathophysiologic processes in CKD.

In a population based cohort of 797 individuals randomly recruited, Gu et al. [30] demonstrated that CE-MS-based urinary proteome analysis not only enables prognosis of progressive loss of kidney function (reduction of eGFR), but that the urine proteome is also associated with and enables prediction of future cardiovascular events, using classifiers that were previously developed as being associated with left ventricular dysfunction [31].

Similarly, a very recent study investigating all available urine samples $(n=737)$ from the 
DIRECT 2 study further confirmed the value of CKD273 [32]. In this study the CKD273-classifier predicted at baseline development of microalbuminuria during follow-up, independent of treatment (candesartan/placebo), age, gender, systolic blood pressure, urine albumin excretion rate, estimated glomerular filtration rate, $\mathrm{HbAlc}$ and diabetes duration, with hazard ratio 2.5 [95\% confidence interval (CI) 1.4-4.3; P = 0.002] and area under the curve 0.79 (95\% CI $0.75-0.84$; $\mathrm{P}$ $<0.0001)$. The CKD273-classifier improved the risk prediction (relative IDI $14 \%, \mathrm{P}=0.002$; cNRI $0.10, \mathrm{P}=0.043$ ).

To identify the specific value of CKD273 at different stages of CKD, Pontillo et al. [33] investigated a total of 2672 patients at different CKD stages the value of albuminuria and CKD273 to predict a steep decline in eGFR ("progressors", $>5 \mathrm{~mL} / \mathrm{min} / 1.73 \mathrm{~m} 2 /$ year). The cohort was divided according to the baseline eGFRs of $\geq 80$, 70-79, 60-69, 50-59, 40-49, 30-39 and $<29 \mathrm{~mL} /$ $\mathrm{min} / 1.73 \mathrm{~m} 2$. At early stage disease CKD273 performed significantly better than albuminuria in detecting progressors, albuminuria performed better in patients with late-stage CKD. The authors concluded that urinary peptides, combined in the CKD273 classifier, allow the detection of progressive CKD at early stages, a point where therapeutic intervention is more likely to be effective.

In all studies published to date a significant improvement over the current state-of ----the-art for CKD273 could be demonstrated, enabling early risk stratification, when therapeutic intervention [34] and prevention of CKD onset is still possible for increased positive outcomes. This is also supported by a recent systematic review that indicates high evidence level for CKD273 [35]. Based on these data demonstrating a clear value of CKD273 and to support this development, the US FDA has recently issued a Letter-of-Support for CKD273 (http://www.fda.gov/downloads/Drugs/ DevelopmentApprovalProcess/UCM508790.pdf ), further underlining the validity of proteomics in patient management.

\section{Proteomic changes appear best suited to display molecular pathophysiology}

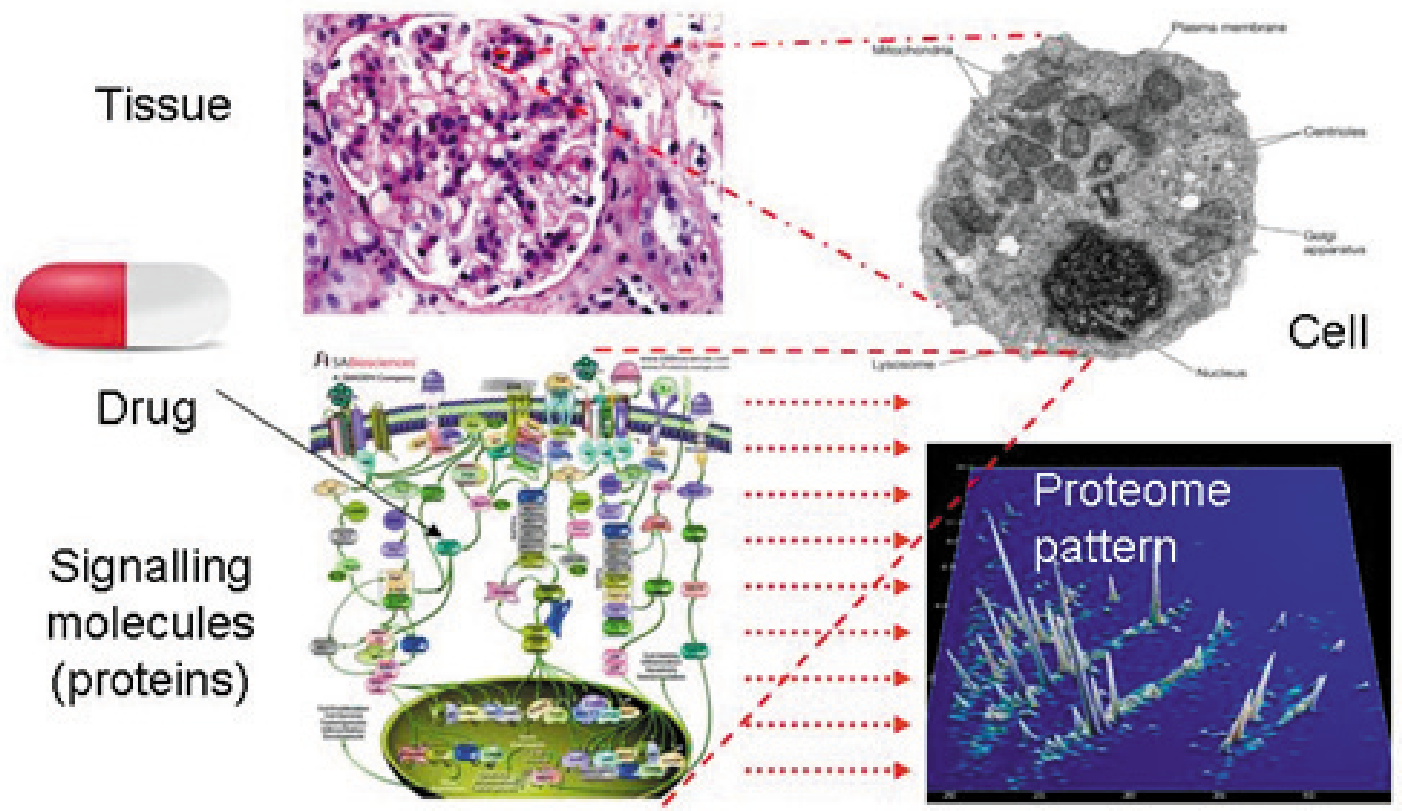

Figure 5. Proteomic changes display molecular pathophysiology. Microscopic investigation of tissue can reveal structural changes. However, subcellular structures, and even more the molecules involved in the molecular pathology, can generally not be assessed. In contrast, urine proteome analysis does not give information on morphological changes, but gives information on global protein changes which can be associated with the molecular changes in disease. Some of these molecules represent the most appropriate targets of therapeutic drugs; hence, proteome analysis can give guidance on the molecular structures to be targeted in therapy. Reprinted from [73] with permission 
In a recent study published by Siwy et al., [36] the potential of CE-MS-based urinary peptide analysis in differentiating between different disease etiologies was presented. The study was based on the hypothesis that distinct molecular changes are the cause of the respective etiologies, and these should also represent the ideal targets for intervention, as previously suggested (Figure 5). The authors investigated data from 1180 urine samples from patients with seven different types of CKD. Potential urinary biomarker peptides specific for distinct etiologies (ranging from 116 to 619 peptides) were defined and combined into SVM-based classifiers specific for each CKD. These classifiers were validated in an independent cohort and showed good to excellent accuracy for discrimination of one CKD type from the others (area under the receiver operating characteristic curve ranged from 0.77 to 0.95 ). The authors concluded that urinary proteome analysis has the potential to identify various types of CKD defined by pathological assessment of renal biopsies and current clinical practice, and that this approach may provide valuable information to unravel crucial molecular changes per CKD.

\section{Other urinary proteomics approaches}

Papale et al. [37] investigated urine proteins from 190 subjects (20 healthy subjects), 20 normoalbuminuric, and 18 microalbuminuric diabetic patients and 132 patients with biopsy-proven nephropathy using a ProteinChip array. The authors were able to differentiate diabetic nephropathy from other CKD with good accuracy in the study, where, ubiquitin and beta-2-microglobulin were identified as biomarker candidates.

Piyaphanee and colleagues [38] aimed at discovering a non-invasive biomarker to distinguish steroid-resistant (SRNS) from steroid-sensitive nephrotic syndrome (SSNS). The authors identified an 11-fold upregulation of a $13.8 \mathrm{kDa}$ fragment of alpha 1-B glycoprotein in urine in SRNS. However, the study was very small, and no validation of the results in an independent cohort has been reported.

Using an array-based proteomic platform, Wu et al. [39] identified elevated angiostatin in SLE patients, which was further confirmed by ELISA. Highest levels were detected in patients with Class IV lupus nephritis. Immunohistochemistry demonstrated angiostatin expression in the tubular cells of these patients. The authors concluded by arguing for further prospective studies to assess the value of angiostatin as biomarker in lupus nephritis.

Using LC-MS/MS and GeLC-MS/MS, Kalantari and colleagues [40] analysed 13 urine samples of patients with biopsy-proven $\operatorname{IgA}$ nephropathy, aiming at identifying prognostic biomarkers. Among other proteins, afamin, leucine-rich alpha-2-glycoprotein, ceruloplasmin, alpha-1-microgolbulin, hemopexin, apolipoprotein A-I, complement C3, vitamin D-binding protein, beta-2-microglobulin, and retinol-binding protein 4 were identified as potential biomarkers. Pathway analysis suggested impairment of extracellular matrix (ECM)-receptor interaction pathways as well as activation of complement and coagulation pathway in progression of IgA nephropathy. With a similar aim, to enable detailed assessment of IgA-N, Graterol et al. [41] investigated the urinary proteome of $19 \operatorname{IgA}-\mathrm{N}$ patients and 16 healthy controls, using affinity beads and MALDI-MS. The authors identified three peptides derived from bradykinin, uromodulin, and alpha-1-antitrypsin, to be associated with disease severity.

Pesic and colleagues investigated urine samples from patients with endemic nephropathy and controls, using 2-D DIGE and mass spectrometry [42]. In this small study the authors identified six proteins (alpha-1-microglobulin, alpha-2-glycoprotein-1, beta-2-microglobulin, mannose-binding-lectin-2, protection-of-telomeresprotein-1, and superoxide-dismutase), which were able to discriminate EN with low and high proteinuria from the controls (sensitivity $66.7-98 \%$ and specificity $70-100 \%$ ). Using the same technique, Lim et al.[43] identified zinc alpha (2) glycoprotein (ZAG) as a urinary biomarker for normo-albuminuric diabetic nephropathy. In a small cohort of 6 subjects per group, ZAG was significantly upregulated (3.44-fold, $\mathrm{P}=0.0026$ ) in non-albuminuric diabetic nephropathy in comparison to diabetics without nephropathy.

Ito-Martin et al. [44] studied the expression of selected TNF superfamily proteins in exosome-like vesicles from cultured human proximal tubular cells and human urine, using LC-MS/MS. The authors detected osteoprotegerin (OPG), a TNF receptor superfamily protein and 21 additional proteins, many extracellular matrix proteins, including the basement membrane proteins type IV collagen, nidogen-1, agrin and fibulin-1. When investigating urine from CKD patients, higher amounts of exosomal protein and exosomal OPG were detected than in urine from healthy volunteers. 
Gonzalez-Calero et al. [45] aimed at identifying urinary biomarkers predictive for albuminuria development in hypertension. Employing 2D DIGE, the authors identified elevated levels of CD59 glycoprotein and alpha-1 antitrypsin (AAT) in patients developing albuminuria. These findings were validated in a prospective study of normoalbuminuric patients who were followed up for 1 year.

\section{Plasma proteomics}

Determination of highly abundant proteins in human plasma has been an attractive research area for many years. A lot of enthusiasm was sparked by a study from Somalogic published in 2010 [46]. The authors of this study claimed that by using an aptamer-based proteomic technology, 60 CKD-specific protein biomarkers could be identified in plasma. Unfortunately, reports on the confirmation of the results of this study are still lacking, shedding doubt on the validity of the results.

An interesting concept was assessed by Holzer and colleagues [47]. Based on the hypothesis that impairment of HDL may contribute to the excess cardiovascular mortality in CKD, the authors employed mass spectrometry and biochemical analyses to study changes in the proteome and lipid composition of HDL from patients on maintenance hemodialysis. This resulted in the detection of a significant increase in the amount of serum amyloid A1, albumin, lipoprotein-associated phospholipase A2, and apoC-III in uremic HDL, and reduced phospholipid and increased triglyceride and lysophospholipid, impairing the ability of uremic HDL to promote cholesterol efflux from macrophages. The authors concluded that the altered composition of HDL in CKD seems to interfere with its cardioprotective properties. In another study following a similar concept, aiming at identifying the cause for the lack of atheroprotective properties of HDL isolated from uremic patients, Weichhart and colleagues identified surfactant protein B (SP-B), apolipoprotein C-II, serum amyloid A (SAA), and alpha-1-microglobulin/bikunin precursor as being enriched in HDL from dialysis patients [48]. Upon further investigation, SAA was found to promote inflammatory cytokine production, and SAA levels in ESRD-HDL inversely correlated with its anti-inflammatory potency. This led to the conclusion that anti-inflammatory activities of HDL are de- fective in uremic patients as a result of specific changes in its molecular composition.

Aiming at detailed characterization of aberrant glycosylation in IgA-N, Takahashi et al. [49] employed activated ion-electron capture dissociation (AI-ECD) Fourier transform ion cyclotron resonance (FT-ICR) tandem mass spectrometry to assess glycosylation of the IgA hinge region, in combination with IgA-specific proteases + trypsin. The authors were able to chart all glycosylation sites using this approach, which may enable defining the molecular events leading to pathogenesis of IgA-N.

Pirodd et al [50] investigated the plasma nitroproteome in CKD, based on the hypothesis that 3'-nitrotyrosine may be sustained by chronic inflammation and oxidative stress in CKD. Combining immunorecognition and LC-MS/MS, the authors demonstrated that plasma proteins of CKD patients showed increased nitration in comparison to healthy controls, while main nitration targets (albumin, fibrinogen chains (A, B and C), transferrin, alpha 1-antitrypsin, complement factor D, haptoglobin, and IgG light and heavy chains), representing the most abundant plasma proteins did not change.

Antonelou and colleagues [51] investigated the oxidative stress status of erythrocytes (RBC) and its association with cellular ultrastructure and membrane proteome modifications in ESRD patients on hemodialysis. As expected RBC from ESRD patients exhibited significantly increased ROS accumulation. Hemodialysis significantly contributed to membrane proteome remodelling, especially for aquaporin-1, peroxiredoxin-2 and ubiquitinated proteins. The intracellular redox status and the closely associated membrane modifications seemed to be related to membrane instability, loss of surface area through vesiculation, echinocytosis and stomatocytosis. Aiming at a similar goal, Varez-Llamas et al. [52] investigated erythrocyte membrane proteins whose expression could be altered in CKD. Employing 2D DIGE, 5 differentially expressed proteins among healthy individuals, non-dialyzed CKD and erythropoietin/dialysis-treated CKD patients were identified (beta-adducin, HSP71/72, tropomodulin-1, ezrin, and radixin). Ezrin and radixin were observed to be higher in dialyzed CKD patients than in the other 2 groups. Beta-adducin was increased in CKD patients (dialyzed or not). A signal corresponding to tropomodulin 1 was found to be of 
higher abundance in non-dialyzed CKD patients compared with controls or dialyzed CKD.

Luczak and colleagues [53] investigated plasma from patients with CKD, having cardiovascular disease (CVD), and controls, to identify molecular similarities between CKD an CVD. Employing 2D Electrophoresis, the authors identified accumulation of alpha-1-microglobulin, apolipoprotein A-IV, gamma-fibrinogen and haptoglobin in CKD, and similar changes in CVD, although direct comparison of CKD and CVD revealed significant differences in the accumulation of alpha-1-microglobulin and apolipoprotein A-IV. The same authors more recently also reported on the comparative proteome analysis of plasma from patients in various stages of CKD, patients with advanced CVD and normal renal function and healthy volunteers [54]. Using 2DE and MS, as well as direct MS for low molecular weight compounds, the authors found deregulation of blood coagulation cascade, the transport, binding and metabolism of lipoproteins and inflammatory processes in CKD and CVD. These results were later confirmed in an additional study [55].

With a similar aim, to identify proteins significantly changed in CKD and ESRD that could inform about CVD, Glorieux at el. [56] performed high-resolution proteome analysis in plasma from patients with stage 2-3 CKD $(\mathrm{n}=14)$ and stage $5 \mathrm{CKD}$ with haemodialysis (HD) $(\mathrm{n}=15)$. The authors assessed over 2000 plasma proteins, of which 127 displayed lower, while 206 displayed higher abundance in the plasma of patients on HD. Molecular pathway analysis confirmed the modification of known processes involved in CKD complications, including decreased haemostasis and increased inflammation, complement activation and vascular damage. Several of the identified proteins, e.g. lysozyme $\mathrm{C}$ and leucine-rich alpha-2 glycoprotein are related to vascular damage and heart failure. This may lead the way towards novel biomarkers for CKD-associated mortality, and a better understanding of the associated pathophysiological processes.

Antonelou et al [57] compared the plasma proteome of dialysis patients to healthy individuals with 36 months follow-up. Duration of hemodialysis was associated with a trend towards increased intracellular hemoglobin concentration, membrane expression of glucose transporter-1 and stomatin, as well as lower levels of circulating stomatocytes. The uremic index variation in long survived patients is accurately reflected in plasma and erythrocyte oxidative stress modifications.

Based on the hypothesis that proteins released as a consequence of kidney damage in CKD and initiate an adaptive humoral immune response to these proteins, Butte and colleagues employed protein microarrays to compare serum antibodies from patients with chronic kidney disease against matched controls [58]. The authors found 38 candidates, and verified a significant increase of auto-antibodies against angiotensinogen and PRKRIP1 in CKD.

\section{Bioinformatics in context of CKD}

Fechete and colleagues performed bioinformatics analysis, using integration of multiple Omics sources to decipher molecular pathophysiology of diabetic nephropathy [59]: Molecular features on DN were retrieved from public domains and consolidated on a human protein interaction network and interpreted on the level of molecular pathways in the light of the pathophysiology of the disease and its clinical context defined as associated biomarkers and drug targets. About 1000 features could be assigned to DN. On the level of molecular pathways, the complement and coagulation cascade, PPAR signaling, and the renin-angiotensin system were linked in the disease descriptor space with biomarkers and targets. The authors concluded that Omics data integration on the level of interaction networks provides a platform for identification of pathway-specific biomarkers and therapy options. A similar approach was recently presented by Krochmal et al. [60]. The authors extracted data from 114 manuscripts on CKD (human case-control studies) and compared 750 differentially expressed proteins identified in urine and 553 unique proteins found in the kidney tissue. To investigate the value of this large proteomics database, the authors investigated the full dataset for proteins specifically associated with diabetic nephropathy. A substantial number of proteins was found to be significant affected, among others BRCA2 and MMP2 upregulated in kidney tissue, and urinary peptides associated with fibrosis and inflammation. Overall, the data presented to date strongly indicate that exploitation of large datasets in bioinformatics-based approaches may be the optimal way forward towards deciphering molecular pathology of CKD, explaining the disease on a molecular level, and guiding intervention $[61,62,63]$ 
Beyond biomarker research

A further application area of clinical proteomics is in the development of therapeutic drugs: to successfully interfere with $\mathrm{CKD}$, and reduce the enormous associated costs, an urgent need of the availability of improved interventional treatment was necessary.

However, development of such treatment and design of respective clinical trials are currently prevented by the very long time course of the disease: The time from early disease onset (where treatment would be most effective) until the endpoint (ESRD or death) is reached (where success of treatment is currently assessed) is in the range of 10-20 years. The expectancy of successful treatment at a later stage (when the endpoint is closer in time, hence duration of a trial is shortened to a few years) currently has faded, based on the available evidence data. Collectively, these facts have a severe impact and it appears development of drugs to combat CKD has been significantly reduced, as trials assessing early intervention based on patient-relevant endpoints just cannot be performed in a meaningful way. This development has apparently also been noted by the regulatory agencies, and the EMA in a recent document proposed CKD stage III as potential endpoint in registration trials [64]. Using ,in addition, effective tools (biomarkers) for strat- ification, like CKD273 [65], the development of effective drugs may find new support. In addition, these biomarkers are now employed to identify the best suited animal model, and generate a so called "humanized model" (animal model that is used to study complex human biological processes) that will enable to test novel drugs in a much more effective, less time-consuming, and consequently less expensive approach [16].

\section{CONCLUSION AND OUTLOOK}

Based on the evidence currently available, it appears that proteome analysis will significantly improve management of CKD. Main areas of application in the context of patient management appear to be development of biomarkers, and identification of appropriate therapeutic targets, as also indicated in Figure 6.

Given the currently available means, little need exists for biomarkers enabling diagnosis of CKD. However, early detection and prognosis of development, as well as differential diagnosis and prediction of drug response are clearly areas of large unmet clinical need. As already demonstrated in several recent publications, protein-based biomarkers significantly improve accuracy of ear-

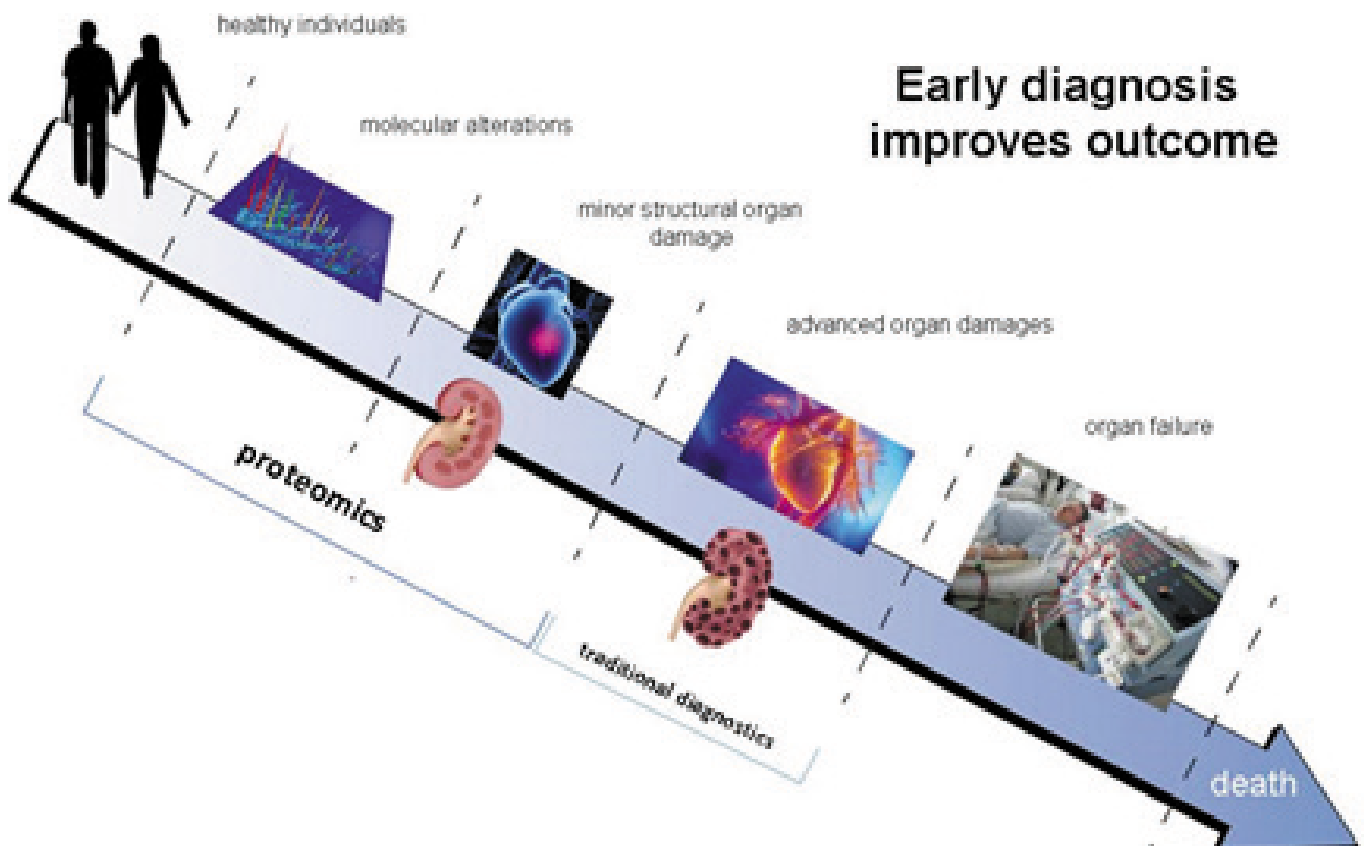

Figure 6. Early diagnosis and/or prognosis of diseases improves chances for a better outcome for the patients. The initiation of molecular processes that result in (chronic) diseases can be detected based on the decisive molecular changes, using proteomic technologies, substantially prior to advanced organ damage. This could allow earlier intervention where drugs are most effective. Reprinted from [67] with permission. 
ly detection and prognosis $[66,67]$. Formally, the implementation of such improved approaches to assess patients more accurately requires the proof of a benefit in a prospective study, like the currently ongoing PRIORITY trial. However, in the light of the overwhelming evidence that early and intensified therapy has a significant positive impact $[68,34]$, and considering a projected health economic benefit [69], it is debatable if implementation should be delayed until the formal demonstration of a benefit from earlier and more accurate diagnosis and prognosis. Delaying implementation in involved in onset and progression of the disease should enable targeted therapeutic intervention. Unfortunately, such knowledge is still lacking, in part due to the complexity of the kidney and the disease, and the general unavailability of suitable specimens. Possible solutions for this issue could be: i) employment of existing transcriptomics data, ii) bioinformatics approaches predicting molecular processes based on observations in accessible body fluids and iii) investigation of tissue from appropriate animal models. Ideally, a combination of all three approaches may be best suited

\section{»Humanized» model concept}

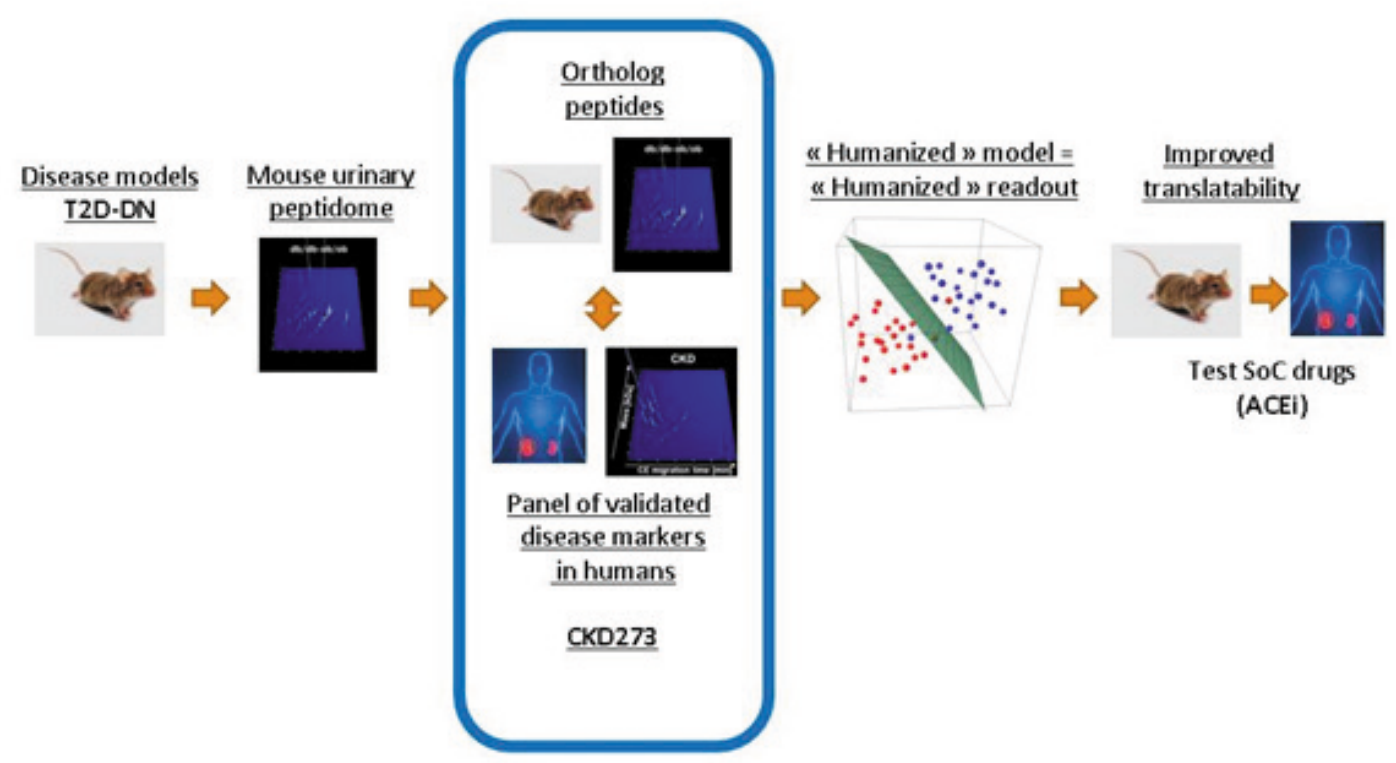

Figure 7. Humanized model concept. Improving the translatability of animal models of disease by the development of a multimolecular humanized readout. The analysis of multiple urinary proteomic changes in the animal model allows identifying, similar (ortholog) changes in human disease and animal models, leading to a "humanized" readout, which will more efficiently translate the effects of new drugs in preclinical models to the clinic. Reprinted from [70] with permission.

turn results in withholding a potential benefit from patients, which cannot be corrected at a later stage, as CKD in later stages is incurable. In the light of the impact of CKD, and associated increased risks for other diseases (e.g. CVD) on life expectancy and quality of life, and considering that curative treatment may be possible at early, but not at later stages, the arguments for implementation appear to outweigh arguments for delaying until full proof of the benefit has been generated.

The second main application of proteomics in CKD appears to be in the context of drug development. Knowledge of the molecular processes to addressing this challenge. A substantial step, especially towards identification of animal models, was the approach recently proposed by Klein and colleagues (Figure 7), where molecular changes associated with CKD in urine were compared between human and different animal models [70]. This approach was sparked by the observation that the ZDF rat does not resemble human DN on a molecular level [71], nevertheless this model is used in preclinical assessment of potential drugs. Since the molecular processes relevant in human are not affected in the animal model, a benefit of intervention cannot be assessed with confidence. However, 
as demonstrated by Klein et al.[70], other animal models appear to reflect human DN well. These animals should not only be the superior model for preclinical assessment, but in-depth investigation of the kidney proteome of these animals may enable identifying the molecular biological processes that are responsible for onset and progression of CKD in human, which may allow identifying truly appropriate therapeutic targets.

In conclusion, proteome analysis is already applied on a yet limited scale in the management of CKD, and it is expected, based on the positive results, that the application of proteomics in this area will increase exponentially. We also anticipate a change in CKD management: from the current strategy to aim at "repairing the damage" towards prevention. As graphically depicted in Figure 6, proteome analysis enables detection of the molecular cause of CKD, at a point in time when no clinical symptoms are evident, and no irreversible damage has occurred (of note: the currently generally employed biomarkers, albuminuria and eGFR, are a consequence of damage, not of the cause). As such, targeted personalized intervention aiming at preventing onset of clinically relevant disease will be possible based on proteome analysis.

\section{Acknowledgments}

This study was supported in part by the European Commission via the PRIORITY project (Health-F2-2011-279277).

Statement of Competing Financial Interests

$\mathrm{HM}$ is the founder and co-owner of Mosaiques Diagnostics $\mathrm{GmbH}$, who developed the CE-MS technology for clinical application. MP is a research scientist employed by Mosaiques Diagnostics GmbH.

\section{REFERENCES}

1. Jha V, Garcia-Garcia G, Iseki K et al. Chronic kidney disease: global dimension and perspectives. Lancet. 2013; 382(9888): 260-272.

2. Pontillo $\mathrm{C}$ and Mischak $\mathrm{H}$. Urinary peptide-based classifier CKD273: towards clinical application in chronic kidney disease. Clinical Kidney Journal. 2017; 10(2): 192-201.
3. Albalat A, Mischak H, and Mullen W. Urine proteomics in clinical applications: technologies, principal considerations and clinical implementation. Prilozi. 2011; 32(1): 13-44.

4. Thongboonkerd V. Proteomic analysis of renal diseases: unraveling the pathophysiology and biomarker discovery. Expert Rev Proteomics. 2005; 2(3): 349-366.

5. Andersen $\mathrm{S}$, Mischak $\mathrm{H}$, Zürbig $P$ et al. Urinary proteome analysis enables assessment of renoprotective treatment in type 2 diabetic patients with microalbuminuria. BMC Nephrol. 2010; 11(1): 29-

6. Stalmach A, Albalat A, Mullen W, and Mischak H. Recent advances in capillary electrophoresis coupled to mass spectrometry for clinical proteomic applications. Electrophoresis. 2013; 34(11): 1452-1464.

7. Pontillo C, Filip S, Borras DM et al. CE-MS-based proteomics in biomarker discovery and clinical application. Proteomics Clin Appl. 2015; 9(3-4): 322-334.

8. Kaiser T, Hermann A, Kielstein J.T. et al. Capillary electrophoresis coupled to mass spectrometry to establish polypeptide patterns in dialysis fluids. $\mathrm{J}$ Chromatogr A. 2003; 1013(1-2): 157-171.

9. Wittke S, Fliser D, Haubitz $M$ et al. Determination of peptides and proteins in human urine with capillary electrophoresis-mass spectrometry, a suitable tool for the establishment of new diagnostic markers. J Chromatogr A. 2003; 1013(1-2): 173-181.

10. Mischak H, Vlahou A, and Ioannidis JP. Technical aspects and inter-laboratory variability in native peptide profiling: The CE-MS experience. Clin Biochem. 2013; 46(6): 432-443.

11. Metzger J, Kirsch T, Schiffer E et al. Urinary excretion of twenty peptides forms an early and accurate diagnostic pattern of acute kidney injury. Kidney Int. 2010; 78(12): 1252-1262.

12. Delles C, Schiffer E, von Zur MC et al. Urinary proteomic diagnosis of coronary artery disease: identification and clinical validation in 623 individuals. J Hypertens. 2010; 28(11): 2316-2322.

13. Lankisch TO, Metzger J, Negm AA et al. Bile proteomic profiles differentiate cholangiocarcinoma from primary sclerosing cholangitis and choledocholithiasis. Hepatology. 2011; 53(3): 875-884.

14. AlkhalafA, Zürbig P, Bakker SJ et al. Multicentric validation of proteomic biomarkers in urine specific for diabetic nephropathy. PLoS One. 2010; 5(10): e13421-

15. Rossing K, Mischak H, Dakna M et al. Urinary proteomics in diabetes and CKD. J Am Soc Nephrol. 2008; 19(7): 1283-1290.

16. Good DM, Zürbig P, Argiles A et al. Naturally occurring human urinary peptides for use in di- 
agnosis of chronic kidney disease. Mol Cell Proteomics. 2010; 9(11): 2424-2437.

17. Dakna M, Harris K, Kalousis A et al. Addressing the challenge of defining valid proteomic biomarkers and classifiers. BMC Bioinformatics. 2010; 11: 594

18. Mischak H, Delles C, Klein J, and Schanstra JP. Urinary proteomics based on capillary electrophoresis-coupled mass spectrometry in kidney disease: discovery and validation of biomarkers, and clinical application. Adv Chronic Kidney Dis. 2010; 17(6): 493-506.

19. Zürbig P, Jerums G, Hovind $P$ et al. Urinary Proteomics for Early Diagnosis in Diabetic Nephropathy. Diabetes. 2012; 61(12): 3304-3313.

20. Roscioni SS, de ZD, Hellemons ME et al. A urinary peptide biomarker set predicts worsening of albuminuria in type 2 diabetes mellitus. Diabetologia. 2012; 56(2): 259-267.

21. Argiles A, Siwy J, Duranton F et al. CKD273, a New Proteomics Classifier Assessing CKD and Its Prognosis. PLoS One. 2013; 8(5): e62837-

22. Ovrehus MA, Zurbig P, Vikse BE, and Hallan SI. Urinary proteomics in chronic kidney disease: diagnosis and risk of progression beyond albuminuria. Clin Proteomics. 2015; 12(1): 21-

23. Molin L, Seraglia R, Lapolla A et al. A comparison between MALDI-MS and CE-MS data for biomarker assessment in chronic kidney diseases. J Proteomics. 2012; 75(18): 5888-5897.

24. Nkuipou-Kenfack E, Duranton F, Gayrard N et al. Assessment of metabolomic and proteomic biomarkers in detection and prognosis of progression of renal function in chronic kidney disease. PLoS ONE. 2014; 9(5): e96955-

25. Siwy J, Schanstra JP, Argiles A et al. Multicentre prospective validation of a urinary peptidome-based classifier for the diagnosis of type 2 diabetic nephropathy. Nephrol Dial Transplant. 2014; 29(8): 1563-1570.

26. Lindhardt M, Persson F, Currie G et al. Proteomic prediction and Renin angiotensin aldosterone system Inhibition prevention Of early diabetic nephRopathy in TYpe 2 diabetic patients with normoalbuminuria (PRIORITY): essential study design and rationale of a randomised clinical multicentre trial. BMJ Open. 2016; 6(3): e010310-

27. Nielsen SE, Persson F, Frandsen E et al. Spironolactone diminishes urinary albumin excretion in patients with type 1 diabetes and microalbuminuria: a randomized placebo-controlled crossover study. Diabet Med. 2012; 29(8): e184-e190.

28. Lindhardt M, Persson FI, Oxlund C. et al. Predicting albuminuria response to spironolactone treatment with urinary proteomics in patients with type 2 diabetes and hypertension. Nephrol Dial Transplant. 2016; in press

29. Schanstra JP, Zurbig P, Alkhalaf A et al. Diagnosis and Prediction of CKD Progression by Assessment of Urinary Peptides. J Am Soc Nephrol. 2015; 26(8): 1999-2010.

30. Gu YM, Thijs L, Liu YP et al. The urinary proteome as correlate and predictor of renal function in a population study. Nephrol Dial Transplant. 2014;

31. Kuznetsova T, Mischak H, Mullen W, and Staessen JA. Urinary proteome analysis in hypertensive patients with left ventricular diastolic dysfunction. Eur Heart J. 2012; 33(18): 2342-2350.

32. Lindhardt M, Persson F, Zurbig P et al. Urinary proteomics predict onset of microalbuminuria in normoalbuminuric type 2 diabetic patients, a substudy of the DIRECT-Protect 2 study. Nephrol Dial Transplant. 2016; in press

33. Pontillo C, Jacobs L, Staessen JA et al. A Urinary proteome-based Classifier for the early Detection of Decline in Glomerular Filtration. Nephrol Dial Transplant. 2016; in press

34. Schievink B, Kropelin T, Mulder S et al. Early renin-angiotensin system intervention is more beneficial than late intervention in delaying endstage renal disease in patients with type 2 diabetes. Diabetes Obes Metab. 2016; 18(1): 64-71.

35. Critselis E and Lambers HH. Utility of the CKD273 peptide classifier in predicting chronic kidney disease progression. Nephrol Dial Transplant. 2016; 31(2): 249-254.

36. Siwy J, Zürbig P, Argiles A et al. Non-invasive diagnosis of chronic kidney diseases using urinary proteome analysis. Nephrol Dial Transplant. 2016; in press

37. Papale M, Di Paolo S, Magistroni R et al. Urine Proteome Analysis May Allow Noninvasive Differential Diagnosis of Diabetic Nephropathy. Diabetes Care. 2010; 33(11): 2409-2415.

38. Piyaphanee N, Ma Q, Kremen O et al. Discovery and initial validation of alpha 1-B glycoprotein fragmentation as a differential urinary biomarker in pediatric steroid-resistant nephrotic syndrome. Proteomics Clinical Applications. 2011; 5(5-6): 334-342.

39. Wu TF, Fu YY, Brekken D et al. Urine Proteome Scans Uncover Total Urinary Protease, Prostaglandin D Synthase, Serum Amyloid P, and Superoxide Dismutase as Potential Markers of Lupus Nephritis. Journal of Immunology. 2010; 184(4): 2183-2193.

40. Kalantari S, Rutishauser D, Samavat S et al. Urinary Prognostic Biomarkers and Classification of IgA Nephropathy by High Resolution Mass Spec- 
trometry Coupled with Liquid Chromatography. PLoS One. 2013; 8(12)

41. Graterol F, Navarro-Munoz M, Ibernon $M$ et al. Poor histological lesions in IgA nephropathy may be reflected in blood and urine peptide profiling. BMC Nephrology. 2013; 14

42. Pesic I, Stefanovic V, Muller GA et al. Identification and validation of six proteins as marker for endemic nephropathy. Journal of Proteomics. 2011; 74(10): 1994-2007.

43. Lim SC, Liying DQ, Toy WC et al. Adipocytokine zinc alpha(2) glycoprotein (ZAG) as a novel urinary biomarker for normo-albuminuric diabetic nephropathy. Diabetic Medicine. 2012; 29(7): 945-949.

44. ito-Martin A, Ucero AC, Zubiri I et al. Osteoprotegerin in Exosome-Like Vesicles from Human Cultured Tubular Cells and Urine. PLoS One. 2013; 8(8)

45. Gonzalez-Calero L, Martin-Lorenzo M, de la Cuesta $\mathrm{F}$ et al. Urinary alpha-1 antitrypsin and CD59 glycoprotein predict albuminuria development in hypertensive patients under chronic renin-angiotensin system suppression. Cardiovascular Diabetology. 2016; 15

46. Gold L, Ayers D, Bertino J et al. Aptamer-based multiplexed proteomic technology for biomarker discovery. PLoS One. 2010; 5(12): e15004-

47. Holzer M, Birner-Gruenberger R, Stojakovic T et al. Uremia Alters HDL Composition and Function. Journal of the American Society of Nephrology. 2011; 22(9): 1631-1641.

48. Weichhart T, Kopecky C, Kubicek M et al. Serum Amyloid A in Uremic HDL Promotes Inflammation. Journal of the American Society of Nephrology. 2012; 23(5): 934-947.

49. Takahashi K, Wall SB, Suzuki H et al. Clustered O-Glycans of IgA1. Molecular \& Cellular Proteomics. 2010; 9(11): 2545-2557.

50. Piroddi M, Palmese A, Pilolli F et al. Plasma nitroproteome of kidney disease patients. Amino Acids. 2011; 40(2): 653-667.

51. Antonelou MH, Kriebardis AG, Velentzas AD et al. Oxidative stress-associated shape transformation and membrane proteome remodeling in erythrocytes of end stage renal disease patients on hemodialysis. Journal of Proteomics. 2011; 74(11): 2441-2452.

52. varez-Llamas G, Zubiri I, Maroto AS et al. A role for the membrane proteome in human chronic kidney disease erythrocytes. Translational Research. 2012; 160(5): 374-383.

53. Luczak M, Formanowicz D, Pawliczak E et al. Chronic kidney disease-related atherosclerosis
- proteomic studies of blood plasma. Proteome Science. 2011; 9

54. Luczak M, Formanowicz D, Marczak L et al. Deeper insight into chronic kidney disease-related atherosclerosis: comparative proteomic studies of blood plasma using 2DE and mass spectrometry. Journal of Translational Medicine. 2015; 13

55. Luczak M, Suszynska-Zajczyk J, Marczak L et al. Label-Free Quantitative Proteomics Reveals Differences in Molecular Mechanism of Atherosclerosis Related and Non-Related to Chronic Kidney Disease. International Journal of Molecular Sciences. 2016; 17(5)

56. Glorieux G, Mullen W, Duranton F et al. New insights in molecular mechanisms involved in chronic kidney disease using high-resolution plasma proteome analysis. Nephrol Dial Transplant. 2015; 30(11): 1842-1852.

57. Antonelou MH, Georgatzakou HT, Tzounakas VL et al. Blood modifications associated with end stage renal disease duration, progression and cardiovascular mortality: a 3-year follow-up pilot study. Journal of Proteomics. 2014; 101: 88-101.

58. Butte AJ, Sigdel TK, Wadia PP et al. Protein Microarrays Discover Angiotensinogen and PRKRIP1 as Novel Targets for Autoantibodies in Chronic Renal Disease. Molecular \& Cellular Proteomics. 2011; 10(3)

59. Fechete R, Heinzel A, Perco P et al. Mapping of molecular pathways, biomarkers and drug targets for diabetic nephropathy. Proteomics Clinical Applications. 2011; 5(5-6): 354-366.

60. Krochmal M, Fernandes M, Filip S et al. PeptiCKDdb-peptide- and protein-centric database for the investigation of genesis and progression of chronic kidney disease. Database-the Journal of Biological Databases and Curation. 2016;

61. Dominiczak AF, Herget-Rosenthal S, Delles C et al. Systems biology to battle vascular disease. Nephrol Dial Transplant. 2010; 25(4): 1019-1022.

62. Molina F, Dehmer M, Perco P et al. Systems biology: opening new avenues in clinical research. Nephrol Dial Transplant. 2010; 25(4): 1015-1018.

63. Cisek K, Krochmal M, Klein J, and Mischak H. The application of multi-omics and systems biology to identify therapeutic targets in chronic kidney disease. Nephrol Dial Transplant. 2015.

64. EMA. http://www.ema.europa.eu/docs/en_GB/ document_library/Scientific_guideline/2014/06/ WC500169469.pdf. 2014;

65. Pontillo C, Zhang Z, Schanstra J et al. Prediction of chronic kidney disease stage 3 by CKD273, a urinary proteomic biomarker. Kidney International Reports. 2017; in press 
66. Mischak H, Delles C, Vlahou A, and Vanholder R. Proteomic biomarkers in kidney disease: issues in development and implementation. Nat Rev Nephrol. 2015; 11(4): 221-232.

67. Stepczynska A, Schanstra JP, and Mischak H. Implementation of CE-MS-identified proteome-based biomarker panels in drug development and patient management. Bioanalysis. 2016; 8(5): 439-455.

68. Andresdottir G, Jensen ML, Carstensen B et al. Improved survival and renal prognosis of patients with type 2 diabetes and nephropathy with improved control of risk factors. Diabetes Care. 2014; 37(6): 1660-1667.

69. Critselis E, Vlahou A, Stel VS, and Morton RL. Cost-effectiveness of screening type 2 diabetes patients for chronic kidney disease progression with the CKD273 urinary peptide classifier as compared to urinary albumin excretion. Nephrol Dial Transplant. 2017; in press

70. Klein J, Ramirez-Torres A, Ericsson A et al. Urinary peptidomics provides a noninvasive humanized readout of diabetic nephropathy in mice. Kidney Int. 2016; in press

71. Siwy J, Zoja C, Klein J. et al. Evaluation of the Zucker Diabetic Fatty (ZDF) rat as a model for human disease based on urinary peptidomic profiles. PLoS One. 2012; 7(12): e51334-

72. Siwy J, Schanstra JP, Argiles A et al. Multicentre prospective validation of a urinary peptidome-based classifier for the diagnosis of type 2 diabetic nephropathy. Nephrology Dialysis Transplantation. 2014; 29(8): 1563-1570.

73. Mischak H. Pro: Urine proteomics as a liquid kidney biopsy: no more kidney punctures! Nephrol Dial Transplant. 2015; 30(4): 532-537. 


\title{
Резиме
}

\section{КЛИНИЧКА ПРОТЕОМИКА ЗА БУБРЕЖНИ ЗАБОЛУВАЊА: ОД ПРОНАОЃАЫЕ ДО КЛИНИЧКА УПОТРЕБА}

\author{
Мартин Пејчиновски, Харалд Мишак
}

Mosaiques Diagnostics GmbH, Хановер, Германија

Употребата на протеомската анализа со години дава нови и значајни молекуларни откритија за дефинирање на хроничните бубрежни заболувања. Генерално, хипотезата на овој приод е дека протеините ја имаат главната улога при правилното функционирање на бубрезите, каде што заболувањето настанува како резултат на значителни промени во дејствувањето на протеините. Утврдување тона главните протеини и нивната улога при појавата на одредено заболување можат за возврат да бидат од големо значење. Тоа може да доведе до одредување на идеални биомаркери, кои ќе претставуваат важна алатка за подобро здраствено згрижување на пациентите со хронични бубрежни заболувања. Исто така, протеомската анализа придонесува за значајни медицински пронајдоци (откритија), кои заедно со примената на биомаркерите можат да помогнат во подобро лекување на пациентите. За таа цел во ова резиме ќе бидат претставени современи научни истражувања за практична примена на клиничката протеомика кај пациентите со хрнонични бубрежни заболувања. Воедно, ќе бидат прикажани и позитивни резултати од самата протеомската анализа при водењето ваков вид пациенти, која се очекува да најде поголема медицинска примена во иднина.

Клучни зборови: протеомска анализа, биомаркери, хронични бубрежни заболувања 